\title{
Geographical distribution of Anthrax using Geographic Information System (GIS) during 2010-2015 in Iran
}

\author{
Behzad Amiri ${ }^{1}$, Ebrahim Ghaderi ${ }^{2 *}(\mathbb{D})$, Parvin Mohamadi ${ }^{3}$, Samira Shirzadi ${ }^{4}$, Shahla Afrasiabian ${ }^{2}$, Heyman Salimi Zand ${ }^{2}$, \\ Asrin Karimi ${ }^{5}$, Elham Goodarzi ${ }^{6}$, Zaher Khazaei ${ }^{7}$, Leili Moayed ${ }^{8}$
}

Received: 14 Feb 2020

Published: 17 Mar 2021

\section{Abstract}

Background: Anthrax is a zoonotic infectious disease that is still considered as a health problem in developing countries. Therefore, the aim of this study was to investigate the incidence and geographical distribution of anthrax using the Geographic Information System (GIS) and predict its incidence in Iran in 2021.

Methods: This study is descriptive analytical study. Information on anthrax was obtained from the Center for Communicable Diseases Control during 2010-2015. In the next step, ArcGIS 9.3 was used to prepare geographic maps of the disease incidence and frequency. Therefore, using the Raster Calculator tool, the disease prediction map was drawn.

Results: The highest incidence of anthrax during 2010-2015 was observed in the provinces of Kurdistan, North Khorasan, and Chaharmahal and Bakhtiari, respectively. The trend of the incidence of anthrax in Iran had increased from 2010 to 2013, while its incidence decreased in 2014. Based on the results of modeling in Iran, the provinces of Kurdistan, West Azarbaijan, Tehran, and Zanjan, respectively, with $37.16 \%, 33.83 \%, 16.78 \%$, and $10.49 \%$ of their area $\left(\mathrm{km}^{2}\right)$ had the highest risk of anthrax disease in the country in the year 2021.

Conclusion: Since the provinces of Kurdistan, West Azerbaijan, Tehran, and Zanjan are among the high-risk areas in the country in the coming years, the cooperation between the veterinary organization and the health care system and the vaccination of livestock in these areas can significantly help to control and prevent the disease.

Keywords: Prediction of the Incidence, Anthrax, GIS, Iran

Conflicts of Interest: None declared

Funding: Kurdistan University of Medical Sciences

\section{*This work has been published under CC BY-NC-SA 1.0 license. \\ Copyright $\odot$ Iran University of Medical Sciences}

Cite this article as: Amiri B, Ghaderi E, Mohamadi P, Shirzadi S, Afrasiabian Sh, Salimi Zand H, Karimi A, Goodarzi E, Khazaei Z, Moayed L. Geographical distribution of Anthrax using Geographic Information System (GIS) during 2010-2015 in Iran. Med J Islam Repub Iran. 2021 (17 Mar);35:36. https://doi.org/10.47176/mjiri.35.36

\section{Introduction}

Anthrax is caused by the gram-positive spore-forming bacilli called Bacillus anthracis, which is an anaerobic bacillus (1). If left untreated, $10 \%$ to $20 \%$ of cases with the disease will die (2). D ue to the implementation of livestock

Corresponding author: Dr Ebrahim Ghaderi, ebrahimghaderi@yahoo.com

1. Department of Zoonotic Disease, Center for Communicable Disease Control, Ministry of Health and Medical Education, Tehran, Iran

2. Zoonoses Research Center, Research Institute for Health Development, Kurdistan University of Medical Sciences, Sanandaj, Iran

3. Department of Medical Sciences, Sanandaj Branch, Islamic Azad University, Sanandaj, Iran

4. Payame Noor University, Tehran, Iran

5. Social Determinants of Health Research Center, Research Institute for Health Development, Kurdistan University of Medical Sciences, Sanandaj, Iran

6. Social Determinants of Health Research Center, Lorestan University of Medical Sciences, Khorramabad, Iran

7. Department of Public Health, School of Medicine, Dezful University of Medical Sciences, Dezful, Iran

8. Cellular and Molecular Research Center, Sabzevar University of Medical Sciences, Sabzevar, Iran vaccination programs and adopting health measures, anthrax is not considered a health problem in developed countries, but it is still a major health concern for developing

$\uparrow$ What is "already known" in this topic:

Anthrax is a zoonotic disease affecting both humans and animals, and its study is extremely important due to its application in military and bioterrorism and the creation of economic and health problems.

$\rightarrow$ What this article adds:

Some of the provinces will be included in the high-risk areas for anthrax by 2021 , indicating the need for more health planning in these areas. 
countries whose economy is largely dependent on agricultural activities. Different types of Anthrax in Iran cause skin, gastrointestinal and respiratory diseases (3).

This disease is prevalent in many parts of the world, including Asia, southern Europe, sub-Saharan Africa, and parts of Australia. Anthrax has worldwide outbreaks; however its incidence and method of spread are different in various parts of the world. According to estimates, in the United States, $80 \%$ of the disease is caused by industry and the remaining $20 \%$ is spread through agricultural activities. It is estimated that between 2,000 and 20,000 cases of human anthrax occur worldwide annually. In addition to India and Pakistan, cases of the disease are reported annually in Bangladesh, Zimbabwe, the United States, South Africa, Iran, Iraq, and Turkey (4-6).

In 2009 and 2010, similar outbreaks were reported in Scotland with 119 cases, England with 5 cases, and Germany with 2 cases $(4,7,8)$.

Studies on the incidence of anthrax in livestock in Iran have shown a decreasing trend. The highest incidence of the disease had been reported between 1995 and 1999. According to a report published by the Center for Disease Control, Ministry of Health and Medical Education, 207 cases of human illnesses were reported in 2012, with the highest number of cases observed in Khorasan and East Azerbaijan provinces (9).

The seasonal pattern of disease confirms the role of environmental factors in the prevalence and incidence of disease; Environmental and climatic factors such as rainfall and temperature play an important role in the incidence of anthrax (10). Some soil factors such as alkaline $\mathrm{pH}$, soil calcium, humidity, and temperature (over $15.5^{\circ} \mathrm{C}$ ) provide environmental conditions suitable for the germination of anthrax spores. Therefore, collecting data on such geographical conditions, it is possible to predict its incidence and prevalence in different regions (11). Therefore, predicting the risk of infection in different areas play an important role in protecting public health and safeguarding wildlife and livestock economy (11).

Geographic Information System (GIS) is used in two areas of health, including epidemiology and health care. The use of GIS is of great importance for the management of health systems and infrastructures and can help to present the spread and activity of diseases. GIS is a practical software that can provide a pattern of geographical distribution for many diseases to investigate the causes and represent the spatial distribution of the disease, both quantitatively and quantitatively. The results can be very helpful in making health care decisions to prevent and control diseases $(12,13)$.

Therefore, since public health issues and disease spread are directly related to the geography of the region and always have a spatial dimension, GIS can play a significant role in managing and planning public health programs and studying disease spread. According to some experts, disease mapping is the first step in designing advanced disease alarm and management systems $(13,14)$. Hence, the aim of the present study was to investigate the geographical distribution of anthrax using the Geographic Information System (GIS) during 2010-2015 in Iran and predict its incidence in the human population in Iran in 2021.

\section{Methods}

This research was conducted as descriptive analytical study, and its results can be practically utilized. The research setting included spatial information and the spread of anthrax in Iran. At first, the data on anthrax from 2010 to 2015 was collected from the Center for Communicable Diseases Control. The data on anthrax was categorized in tables in terms of frequency and incidence in each year, and the incidence rate was calculated for cases per 100,000 population in the country. In the next stage, GIS software was used to prepare geographical maps and assess the incidence and frequency of the disease. To prepare the spatial database for the disease, the research team used the vector map of the country prepared in 2017 by the National Mapping Organization (to link descriptive information related to the disease with the spatial data, a GIS mapping was prepared and its accuracy was assessed using Google earth software). After preparing the geographic database of the disease, descriptive data such as incidence and frequency of the disease was added to the GIS descriptive table using Excel software. In the next stage, using GIS software and Symbology functions, a spatial analysis was conducted to prepare a map of the distribution of disease incidence and frequency from 2009 to 2014 . In order to interpolate the disease status throughout Iran, the disease file type was converted to dot format using the Feature to point tool (dot file type was required for map the interpolation). Using the data on each province, the map of the disease incidence and frequency was prepared for the whole country. Finally, in order to draw a map for the prediction of the future status of the disease, it was assumed that the regions with the highest incidence of the disease in a statistical period, have the highest probability of disease occurrence. Therefore, the Raster calculator tool was used to multiply a phase map of the disease within a specific period by a disease incidence map, and finally, a disease prediction map for the future was plotted. The most likely areas at the risk of disease incidence are shown with red color on the map (15). With the information of each province available, the incidence and frequency of disease were developed for the whole country. In order to plot the map of interpolation, the inverse distance interpolation (IDW) method was used (16).

\section{High-risk points analysis}

The Getis-Ord-Gi* statistic was used for the appropriate spatial distribution of hot and cold spots. A disease is recognized as a hot spot when its figures and those of its surrounding conditions are fairly high. When the Getis-Ord$\mathrm{Gi}^{*}$ statistic is calculated to be $1,2,3$, the confidence interval is estimated at $99 \%, 95 \%, 90 \%$, respectively (17).

Since the incidence data are obtained based on the findings of the routine healthcare system, the difference in incidence that was observed in different provinces can be largely dependent on the sensitivity of the healthcare system to record and report cases in these provinces. 


\section{Results}

The results of the study showed that more than half of the patients were male, with $85.5 \%$ of patients living in rural areas. The results of the study showed that most of the diagnosed cases $(58 \%)$ were cutaneous, and $95 \%$ of patients had recovered and only $0.3 \%$ of patients had died (Table 1 ).

The results of the study showed that from 2010 to 2015, the largest numbers of diagnosed diseases were observed in June, July, and August (Fig. 1).

The results of the study showed that the highest incidence of anthrax disease during the years 2010-2015 was observed in the provinces of Kurdistan, North Khorasan, and Chaharmahal Bakhtiari (Table 2).

The results of the study showed that the incidence of anthrax in Iran increased from 2009 to 2013 and decreased in 2014 (Fig. 2).

The GIS maps show the incidence of anthrax in different provinces from 2010 to 2015 (Fig. 3).

According to the latest data on the incidence of the disease (incidence in 2015), North Khorasan and West Azerbaijan provinces had the highest incidence in 2015. Based on the data presented in GIS maps of the whole country, $3.3 \%$ of the total area of the country $\left(54,401.6 \mathrm{~km}^{2}\right)$ which covers parts of 17 provinces (Isfahan, East Azerbaijan, West Azerbaijan, Tehran, Chaharmahal Bakhtiari, Khorasan Razavi, North Khorasan, Zanjan, Semnan, Fars, Kurdistan, Kermanshah, Guilan, Lorestan, Mazandaran, Markazi, and Yazd) is at high risk of developing anthrax in the coming years (2021). Based on the results of modeling, Kurdistan, West Azerbaijan, Tehran and Zanjan provinces, respectively, with $37.16 \%, 33.83 \%, 16.78 \%$, and $10.49 \%$ of their area $\left(\mathrm{Km}^{2}\right)$, are the places with the highest risk of anthrax disease in the coming years (Fig. 4).
Table 1. Demographic data of the participants studied during 20102015

\begin{tabular}{|c|c|c|}
\hline Variable & & $\begin{array}{c}\text { Frequency } \\
(\%)\end{array}$ \\
\hline Gender & $\begin{array}{l}\text { Female } \\
\text { Male }\end{array}$ & $\begin{array}{l}564(48.1) \\
609(51.9)\end{array}$ \\
\hline \multirow{5}{*}{$\begin{array}{l}\text { Location of resi- } \\
\text { dence }\end{array}$} & & $170(14.5)$ \\
\hline & Rural area & $1003(85.5)$ \\
\hline & Housewife & $490(41.8)$ \\
\hline & Ranchman & $199(17)$ \\
\hline & Farmer & 175 (14.9) \\
\hline \multirow[t]{3}{*}{ Occupation } & $\begin{array}{l}\text { Butcher working in a } \\
\text { butchery }\end{array}$ & $18(1.8)$ \\
\hline & Other & $291(24.5)$ \\
\hline & Iranian & $1162(99.1)$ \\
\hline \multirow[t]{2}{*}{ Nationality } & Afghan & $11(0.9)$ \\
\hline & Treatment & $1115(95.1)$ \\
\hline \multirow[t]{4}{*}{ Disease outcome } & Death & $4(0.3)$ \\
\hline & Unknown & $54(4.6)$ \\
\hline & Cutaneous & $680(58)$ \\
\hline & Respiratory & $2(0.2)$ \\
\hline \multirow[t]{2}{*}{ Type of disease } & \multirow{2}{*}{$\begin{array}{l}\text { Cutaneous-respiratory } \\
\text { Unknown }\end{array}$} & $1(0.1)$ \\
\hline & & $490(41.8)$ \\
\hline \multirow{4}{*}{$\begin{array}{r}\text { January } \\
\text { November } \\
\text { September } \\
\text { July } \\
\text { May } \\
\text { March }\end{array}$} & $\begin{array}{rr}H & 28 \\
H & 31 \\
H & 36 \\
H & 33 \\
H & \\
H & \end{array}$ & \\
\hline & $\begin{array}{ll}12 \\
\end{array}$ & \\
\hline & $+H 118$ & \\
\hline & & \\
\hline 0 & 100 & 300 \\
\hline
\end{tabular}

Fig. 1. Frequency of reported cases of disease by month of reporting during 2010-2015

\begin{tabular}{|c|c|c|c|c|c|c|c|}
\hline No. & Province & 2010 & 2011 & 2012 & 2013 & 2014 & 2015 \\
\hline 1 & East Azarbaijan & 0.16 & 0.11 & 0.21 & 0.69 & 0.76 & 0.44 \\
\hline 2 & West Azarbaijan & 0.26 & 0.49 & 1.67 & 2.03 & 1.91 & 2.04 \\
\hline 3 & Ardebil & 0.00 & 0.00 & 0.08 & 0.00 & 0.00 & 0.08 \\
\hline 4 & Esfahan & 0.08 & 0.18 & 0.26 & 0.66 & 0.96 & 0.50 \\
\hline 5 & Alborz & 0.00 & 0.00 & 0.24 & 0.00 & 0.04 & 0.00 \\
\hline 6 & Eilam & 0.00 & 0.00 & 0.00 & 0.00 & 0.00 & 0.00 \\
\hline 7 & Boshehr & 0.00 & 0.00 & 0.00 & 0.00 & 0.00 & 0.00 \\
\hline 8 & Tehran & 0.02 & 0.02 & 0.07 & 0.06 & 0.06 & 0.09 \\
\hline 9 & Cheharmahal Bakhtiari & 0.45 & 1.34 & 1.11 & 1.31 & 0.65 & 0.96 \\
\hline 10 & South Khorasan & 0.30 & 0.15 & 0.13 & 0.00 & 0.26 & 0.13 \\
\hline 11 & Khorasan Razavi & 0.25 & 0.25 & 0.33 & 0.42 & 0.18 & 0.25 \\
\hline 12 & North Khorasan & 0.82 & 0.46 & 0.91 & 0.68 & 1.78 & 1.76 \\
\hline 13 & Khozestan & 0.09 & 0.00 & 0.04 & 0.00 & 0.04 & 0.02 \\
\hline 14 & Zanjan & 0.50 & 0.30 & 0.29 & 0.19 & 0.19 & 0.47 \\
\hline 15 & Semnan & 0.48 & 0.00 & 0.16 & 0.00 & 0.30 & 0.00 \\
\hline 16 & Sistan o Baluchestan & 0.00 & 0.00 & 0.00 & 0.00 & 0.00 & 0.00 \\
\hline 17 & Fars & 0.37 & 0.28 & 0.34 & 0.23 & 0.06 & 0.06 \\
\hline 18 & Ghazvin & 0.00 & 0.00 & 0.66 & 0.00 & 0.00 & 0.56 \\
\hline 19 & Ghom & 0.00 & 0.00 & 0.09 & 0.00 & 0.08 & 0.08 \\
\hline 20 & Kurdistan & 0.41 & 1.47 & 1.06 & 0.73 & 1.38 & 0.91 \\
\hline 21 & Kerman & 0.07 & 0.07 & 0.00 & 0.13 & 0.10 & 0.03 \\
\hline 22 & Kermanshah & 0.16 & 0.21 & 0.36 & 0.36 & 0.15 & 0.05 \\
\hline 23 & Kohgiloyeh o Boirahmad & 0.00 & 0.30 & 0.60 & 0.15 & 0.58 & 0.00 \\
\hline 24 & Golestan & 0.00 & 0.17 & 0.06 & 0.16 & 1.12 & 0.42 \\
\hline 25 & Guilan & 0.16 & 0.36 & 0.32 & 0.20 & 0.44 & 0.16 \\
\hline 26 & Lorestan & 0.23 & 0.34 & 0.17 & 0.00 & 0.00 & 0.06 \\
\hline 27 & Mazandaran & 0.23 & 0.16 & 0.26 & 0.06 & 0.22 & 0.28 \\
\hline 28 & Markazi & 0.00 & 0.28 & 0.35 & 0.14 & 0.21 & 0.34 \\
\hline 29 & Hormozgan & 0.00 & 0.06 & 0.06 & 0.00 & 0.00 & 0.00 \\
\hline 30 & Hamadan & 0.17 & 0.11 & 0.11 & 0.11 & 0.11 & 0.00 \\
\hline 31 & Yazd & 0.00 & 0.00 & 0.00 & 0.00 & 0.09 & 0.00 \\
\hline --. & Iran & 0.14 & 0.18 & 0.28 & 0.29 & 0.34 & 0.28 \\
\hline
\end{tabular}




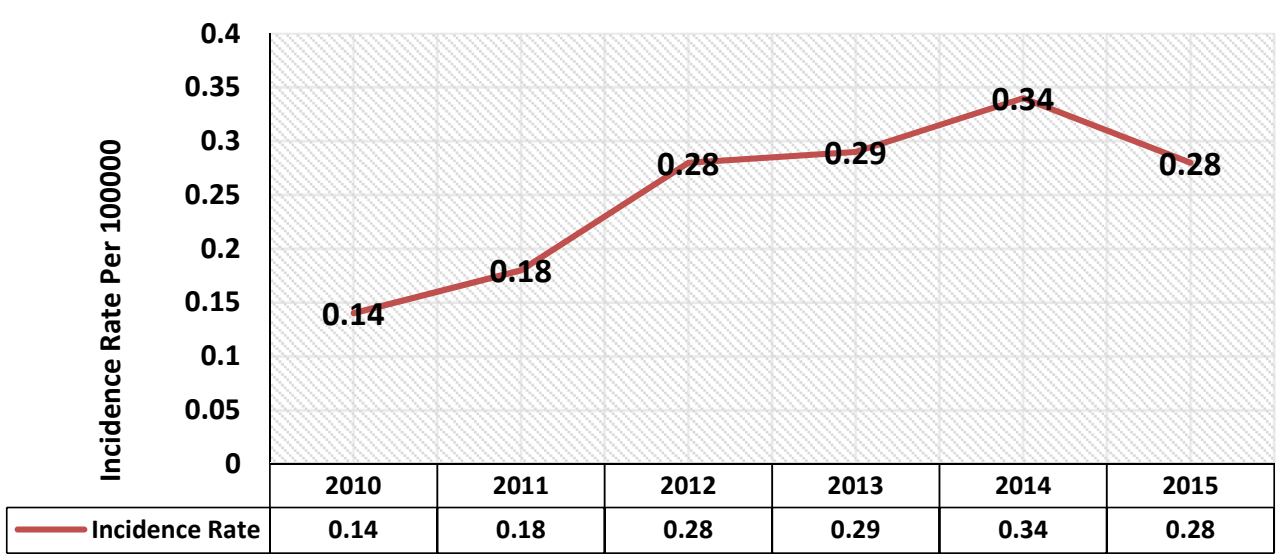

Fig. 2. The trend of the incidence of anthrax disease in Iran during 2010-2015
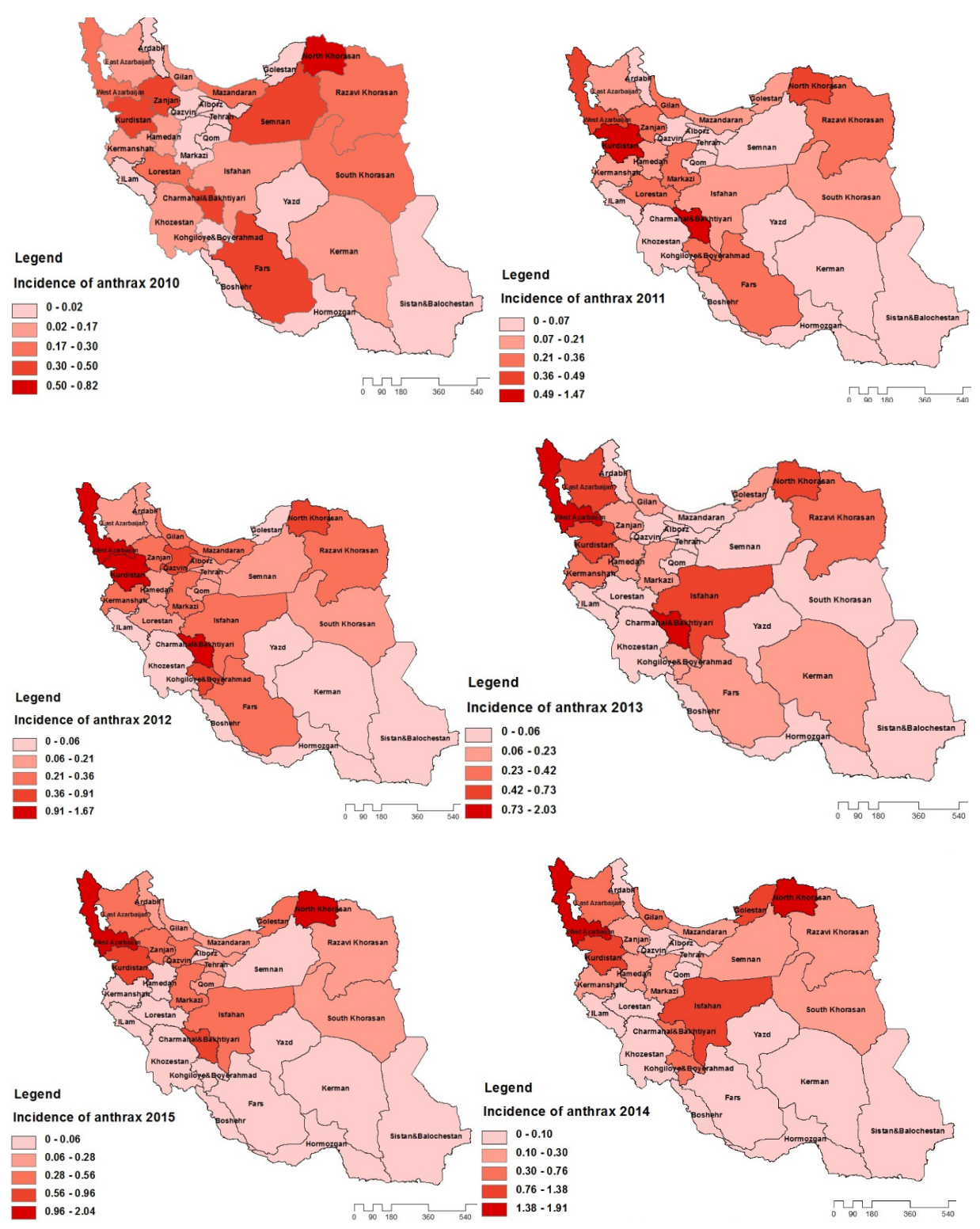

Fig. 3. Maps of the incidence of anthrax disease in Iran from 2010-2015 


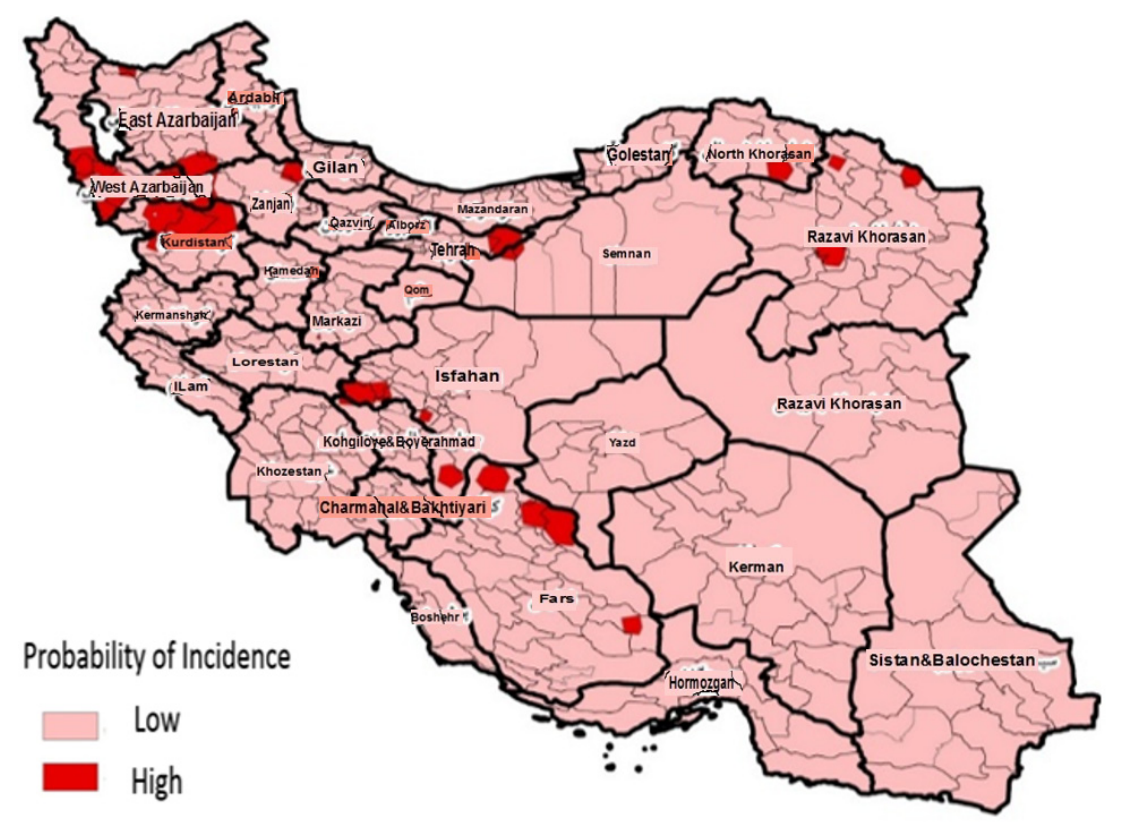

Fig. 4. Predicting high risk areas for anthrax in Iran in 2021

\section{Discussion}

The results of our study showed that the highest incidence of anthrax in Iran during 2010-2015 was observed in Kurdistan, North Khorasan, and Chaharmahal and Bakhtiari provinces, respectively. The trend of the incidence of anthrax in Iran was increasing from 2010 to 2013 and it decreased in 2015. Based on the results of modeling in Iran, Kurdistan, West Azarbaijan, Tehran, and Zanjan provinces with $37.16 \%, 33.83 \%, 16.78 \%$, and $10.49 \%$ of their area, respectively, are the most high risk areas for anthrax in the coming years.

Environmental and climatic conditions are recognized as important factors involved in the incidence of the disease. Because of the varying patterns of the incidence of disease and related mortality, it is of great importance to understand disease epidemiology and predict disease incidence across and within different ecosystems (11). Soil alkalinity and weather conditions are used as spatial and temporal predictors of infection and disease outbreaks. Alkaline soils with high levels of calcium are important geographical determinants of the increase in the incidence of disease and can provide favorable environmental conditions for spores to persist for decades and transmit to animals (10). Soils with a pH above 6.1 are the most important geographical determinants of anthrax that is due to the increase in spore viability $(11,18)$. Similar studies have shown that environmental variables such as temperature, precipitation, soil, and vegetation are important factors involved in the distribution of the incidence of this disease $(19,20)$.

The results of our study showed that the highest incidence of anthrax in Iran during 2009-2015 was observed in Kurdistan, North Khorasan, and Chaharmahal and Bakhtiari provinces, respectively. Areas with moderate and cold whether are suitable zones for the survival of resistant anthrax spores, which can remain in the environment for many years and play an important role in spreading the disease in these areas. Due to the prosperity of the livestock and agriculture industry and the presence of nomadic population, in such areas there are suitable conditions for the transfer of spores to livestock and ultimately to humans. Since anthrax is an occupational disease, livestock-related occupations are more likely to develop the disease, so it is more likely to occur in areas with more livestock, such as the northeast and central parts of the country $(21,22)$.

The results of the study showed that the trend of the incidence of anthrax in Iran increased from 2010 to 2013 and decreased in 2015. Based on the results of modeling in Iran, the provinces of Kurdistan, West Azerbaijan, Tehran, and Zanjan are at the highest risk for the disease in the coming years. These provinces are expected to have the largest areas at the risk for the disease in the coming years, which could be due to the favorable environmental conditions for the spread of spores, intensified by livestock and agricultural practices in these areas.

Dense livestock breeding systems, livestock's increased susceptibility to various diseases, sporadic and inadequate information of breeders, lack of disease detection facilities, inadequate care systems, and large population of livestock are among the items which make the country more vulnerable in these areas; the mentioned items can justify the increase in the incidence of the disease between 2010 and 2013. As compared with the previous years, the incidence of the disease in 2015 has decreased which might be due to the development of veterinary networks across the county and the delivery of animal vaccination services in different areas of the country (23). Problems of communicable disease surveillance system are very similar and often underreporting in worldwide. There are common in vaccine-preventable diseases (24). It can be a limitation of our study. The attention and strengthening of the surveillance system 
is recommended to increase sensitivity of diagnosis and reporting of these diseases.

\section{Conclusion}

Since the provinces of Kurdistan, West Azerbaijan, Tehran, and Zanjan are among the high risk areas in the country in the coming years, the cooperation between the veterinary organization and the health care system and the vaccination of livestock in these areas can significantly help to control and prevent the disease. Conducting studies in these areas of the country in order to discover the causal relationships can also help to understand the epidemiology of the disease in these areas.

\section{Acknowledgments}

This research is the result of a research project with ethics code IR.MUK.REC.1395.184 approved by Kurdistan University of Medical Sciences. The authors would like to express their thanks to the Center for Communicable Diseases Management, Ministry of Health and Medical Education, esteemed Deputies of Health Affairs of the Medical Sciences Universities, responsible experts and the staff working in Communicable Diseases Prevention and Control Departments, experts and Behvarzes working in health centers and health houses across the country, as well as all people who helped us to carry out this project.

\section{Conflict of Interests}

The authors declare that they have no competing interests. distribution of human brucellosis in kohgiluyeh and Boyer-Ahmad Province during 2011-2017. Adv Hum Biol. 2020;10(1):22.

14. Rezaeian M, Dunn G, St Leger S, Appleby L. Geographical epidemiology, spatial analysis and geographical information systems: a multidisciplinary glossary. J Epidemiol Commun Health. 2007;61(2):98-102.

15. Khoshdel A, Nouri Fard M, Pezeshkn R, AR. SM. Mapping of important diseases communicable in Iran. JHAD. 2012;1(1):31-46.

16. Setianto A, Setianto A, Triandini T, Triandini T. Comparison of kriging and inverse distance weighted (IDW) interpolation methods in lineament extraction and analysis. J SE Asian Appl Geol 2013;5(1):219.

17. Getis A, Ord JK. The analysis of Spatial Association by use of Distance Statistics. Geogr Anal. 1992;24(3):189-206.

18. Dragon DC, Rennie RP. The ecology of anthrax spores: tough but not invincible. Can Vet J. 1995;36(5):295.

19. Blackburn JK, McNyset KM, Curtis A, Hugh-Jones ME. Modeling the geographic distribution of Bacillus anthracis, the causative agent of anthrax disease, for the contiguous United States using predictive ecologic niche modeling. Am J Trop Med Hyg. 2007;77(6):1103-10.

20. Lewerin SS, Elvander M, Westermark T, Hartzell LN, Norström AK, Ehrs S, et al. Anthrax outbreak in a Swedish beef cattle herd-1st case in 27 years: Case report.. Acta Vet Scand. 2010;52(1):7.

21. Esmaeli H, Zareei A, Hamidian Z, Ailghazei N, Fatemi M. Cutaneous anthrax epidemic outbreak reported in the villages of city functions Esfaraien North Khorasan Province. J nfect Dis Tropical Med. 2015;15(48):23.

22. Garofolo G, Ciammaruconi A, Fasanella A, Scasciamacchia S, Adone $\mathrm{R}$, Pittiglio V, et al. SNR analysis: molecular investigation of an anthrax epidemic. BMC Vet Res. 2010;6(1):11.

23. Ramezanpoor J, Abaspoor NR, Hajari A, Fadaei NR. An epidemiologic study of human antraz in counties under the supervision of isfahan university of medical sciences during 2012-2015. Mil Caring Sci. 2017; 4(3):178-186

24. Janati A, Hosseiny M, Gouya MM, Moradi G, Ghaderi E. Communicable disease reporting systems in the world: a systematic review article. Iran J Public Health. 2015;44(11):1453.

\section{References}

1. Vieira AR, Salzer JS, Traxler RM, Hendricks KA, Kadzik ME, Marston $\mathrm{CK}$, et al. Enhancing surveillance and diagnostics in anthrax-endemic countries. Emerg Infect Dis. 2017;23(Suppl 1):S147.

2. Hashemi SA, Azimian A, Nojumi S, Garivani T, Safamanesh S, Ghafouri M. A case of fatal gastrointestinal anthrax in north eastern Iran. Case Rep Infect Dis 2015;2(1):2-4.

3. Rao TN, Venkatachalam K, Ahmed K, Padmaja IJ, Bharthi M, Rao PA. A mini outbreak of cutaneous anthrax in Vizianagaram district, Andhra Pradesh, India. Indian J Dermatol VE. 2009;75(4):416.

4. Li L, Yang Y, Wang H, Dong J, Zhao Y, He J, et al., editors. Monitoring method of cow anthrax based on gis and spatial statistical analysis. International Conference on Computer and Computing Technologies in Agriculture; 2009: Springer.

5. Siamudaala VM, Bwalya JM, Munang'andu HM, Sinyangwe PG, Banda F, Mweene AS, et al. Ecology and epidemiology of anthrax in cattle and humans in Zambia. Jpn J Vet 2006;54(1):15-23.

6. Goel AK. Anthrax: a disease of biowarfare and public health importance. World J Clin Cases. 2015;3(1):20.

7. Beyer W, Turnbull P. Anthrax in animals. Mol Aspects Med. 2009;30(6):481-9.

8. Ghabouli M. Acute hemorrhagic ascites and fulminant sepsis due to anthrax. Arch Iran Med. 2004;7(2):140-145

9. Hatami H, Ramezan KA, Mansouri F. Two cases of gastrointestinal anthrax with an unusual presentation from Kermanshah (western Iran). Arch Iran Med. . 2010; 13(2):156-159

10. Hampson K, Lembo T, Bessell P, Auty H, Packer C, Halliday J, et al Predictability of anthrax infection in the Serengeti, Tanzania. J Appl Ecol. 2011;48(6):1333-44.

11. Hugh-Jones M, Blackburn J. The ecology of Bacillus anthracis. Mol. Aspects Med. 2009;30(6):356-67.

12. Nykiforuk CI, Flaman LM. Geographic information systems (GIS) for health promotion and public health: a review. Health Promot Pract. 2011;12(1):63-73.

13. Pordanjani SR, Atamaleki A, Amiri M, Khazaei Z, Fallahzadeh H, Alayi R, et al. Study on epidemiological status, spatial and temporal 